\title{
Source directionality of ambient seismic noise inferred from three-component beamforming
}

\author{
Y. Behr, ${ }^{1,2,7}$ J. Townend, ${ }^{2}$ M. Bowen, ${ }^{3}$ L. Carter, ${ }^{4}$ R. Gorman, ${ }^{5}$ L. Brooks, ${ }^{6}$ and \\ S. Bannister ${ }^{7}$
}

Received 18 April 2012; revised 18 September 2012; accepted 29 October 2012; published 31 January 2013.

[1] The increased use of ambient seismic noise for seismic imaging requires better understanding of the ambient seismic noise wavefield and its source locations and mechanisms. Although the source regions and mechanisms of Rayleigh waves have been studied extensively, characterization of Love wave source processes are sparse or absent. We present here the first systematic comparison of ambient seismic noise source directions within the primary ( $\sim 10-20$ s period) and secondary $(\sim 5-10$ s period $)$ microseism bands for both Rayleigh and Love waves in the Southern Hemisphere using vertical- and horizontalcomponent ambient seismic noise recordings from a dense temporary network of 68 broadband seismometers in New Zealand. Our analysis indicates that Rayleigh and Love waves within the primary microseism band appear to be mostly generated in different areas, whereas in the secondary microseism band they arrive from similar backazimuths. Furthermore, the source areas of surface waves within the secondary microseism band correlate well with modeled deep-water and near-coastal source regions.

Citation: Behr Y., J. Townend, M. Bowen, L. Carter, R. Gorman, L. Brooks, and S. Bannister (2013), Source directionality of ambient seismic noise inferred from three-component beamforming, J. Geophys. Res. Solid Earth, 118, 240-248, doi:10.1029/2012JB009382.

\section{Introduction}

[2] Recent studies employing ambient seismic noise as an energy source have extended our knowledge of crustal and upper mantle structures [Shapiro and Campillo, 2004; Shapiro et al., 2005; Yang et al., 2007; Yao et al., 2006; Lin et al., 2008; Nishida et al., 2008b; Liang and Langston, 2009; Behr et al., 2010, 2011] and time-varying processes [Sens-Schönfelder and Wegler, 2006; Brenguier et al., 2008; Wegler et al., 2009; Mordret et al., 2010]. It has also been demonstrated that the combination of earthquake and ambient seismic noise signals has the potential to overcome

\footnotetext{
All Supporting Information may be found in the online version of this article.

${ }^{1}$ Swiss Seismological Service, ETH Zurich, Sonneggstrasse 5CH-8092, Zurich, Switzerland.

${ }^{2}$ School of Geography, Environment and Earth Sciences, Victoria University of Wellington, PO Box 600, Wellington 6140, New Zealand.

${ }^{3}$ School of Environment, University of Auckland, Private Bag 92019, Auckland, New Zealand.

${ }^{4}$ Antarctic Research Centre, Victoria University of Wellington, PO Box 600, Wellington 6140, New Zealand.

${ }^{5}$ National Institute of Water and Atmospheric Research, PO Box 11115, Hamilton, New Zealand.

${ }^{6}$ School of Mechanical Engineering, The University of Adelaide, SA, 5005, Australia.

${ }^{7}$ GNS Science, PO Box 30-368, Lower Hutt, New Zealand.

Corresponding Author: Y. Behr, Swiss Seismological Service, ETH Zurich, Sonneggstrasse 5, CH-8092, Zurich, Switzerland.

(yannik.behr@sed.ethz.ch)

(C)2012. American Geophysical Union. All Rights Reserved. 2169-9313/13/2012JB009382
}

restrictions inherent to traditional event-based seismology [Stachnik et al., 2008; Lin and Ritzwoller, 2010; Curtis et al., 2012]. Early ambient noise studies focused mainly on the Rayleigh waves contained in vertical noise recordings [Shapiro and Campillo, 2004; Lin et al., 2007]. Recently, however, Love waves contained in transverse noise recordings [Lin et al., 2008] and, in particular, the difference between Love and Rayleigh wave speeds as a measure of radial anisotropy [Moschetti et al., 2010; Huang et al., 2010], have gained increasing attention. Furthermore, the sensitivities to changes in shear velocity at a particular depth of Rayleigh and Love waves of identical periods are significantly different. Love waves therefore contribute complementary information when inverting surface wave speeds for the distribution of shear velocity with depth $[A k i$ and Richards, 2002].

[3] Uncertainty in the source locations and source mechanisms of ambient seismic noise constitutes an obstacle in interpreting results from seismic noise investigations [Tsai, 2009; Harmon et al., 2010; Tsai, 2010]. Most studies addressing the problem of noise source distribution have restricted their analysis of ambient noise source characterization to verticalcomponent seismic recordings [Stehly et al., 2006; Yang and Ritzwoller, 2008; Kedar et al., 2008; Harmon et al., 2010] or have focused on the dominant noise source direction [Roux, 2009; Roux et al., 2011] and a comprehensive theoretical treatment of the excitation of transversely polarized seismic waves remains to be developed [Kedar, 2011].

[4] Gorman et al. [2003] described New Zealand's ocean wave climate as one of the most energetic on Earth, a consequence of its generation by strong westerly winds originating 
in the Southern Ocean and occasional ex-tropical cyclones from the north. These result in a highly energetic ambient seismic noise wavefield [Petersen et al., 2011; Rastin et al., 2012] and make New Zealand an ideal location in which to study its generation.

[5] Several localized studies have previously addressed the relationship between ocean wave state and microseismic recordings in New Zealand. Kibblewhite and Ewans [1985] observed a strong correlation between temporal variations in ocean wave and seismic spectra for signals recorded onshore and offshore in the western North Island. Tindle and Murphy [1999] compared ocean wave significant wave heights with the seismic significant wave heights computed from seismic waves recorded in Auckland and ocean waves recorded off the west coast of the North Island. They found that peaks in the seismic significant wave height coincided with peaks in the ocean significant wave height for the prevailing westerly winds but not for winds from north to east directions.

[6] In this study, we apply plane-wave beamforming to vertical- and horizontal-component seismic noise recordings within the period bands of the primary and secondary microseisms to investigate the source regions and source mechanisms of both Rayleigh and Love waves contained in the ambient seismic noise wavefield. To our knowledge, this is the first study to systematically compare source backazimuths of transverse- and vertical-component ambient seismic noise beamformer results within the primary and secondary microseism bands.

\section{Methods}

[7] We have applied plane-wave beamforming to threecomponent ambient seismic noise data recorded at 68 broadband seismographs in the Taranaki region of the western North Island, New Zealand, between March and September 2002 [Sherburn and White, 2005, and Figure 1]. Of the 68 stations a maximum of 58 were operating at any one time. Guralp CMG-6TD and CMG-40 T seismographs were used, which have a flat velocity response between 0.03 and $50 \mathrm{~Hz}$ (see Figures S1 and S2 in the auxiliary material for operation times of each station and the number of stations per day and S3 for examples of noise power spectral densities.)

[8] We use a plane-wave beamforming algorithm in the frequency domain formulated by Johnson and Dudgeon [1993] and implemented by Brooks et al. [2009]:

$$
P(\vec{k})=\frac{1}{M^{2}} \mathbf{e}^{\dagger} \mathbf{W} \mathbf{Y} \mathbf{Y}^{\dagger} \mathbf{W}^{\dagger} \mathbf{e}
$$

For an array of $M$ stations, $\mathbf{e}$ is an $M \times 1$ vector of phase shifts corresponding to a presumed wave vector $\vec{k} ; \mathbf{W Y}$ is an $M \times N$ vector of windowed Fourier transforms of the ambient seismic noise recordings, where $N$ is the number of samples within the window $W ; \dagger$ denotes complex conjugation; and $P(\vec{k})$ is the beamformer's steered response power [Johnson and Dudgeon, 1993]. Equation (1) can be rewritten as

$$
P(\vec{k})=\frac{1}{M^{2}} \mathbf{e}^{\dagger} \mathbf{C e}
$$

in which $\mathbf{C}=\mathbf{W} \mathbf{Y} \mathbf{Y}^{\dagger} \mathbf{W}^{\dagger}$ denotes the $M \times M$ cross-covariance matrix of the windowed Fourier transforms.

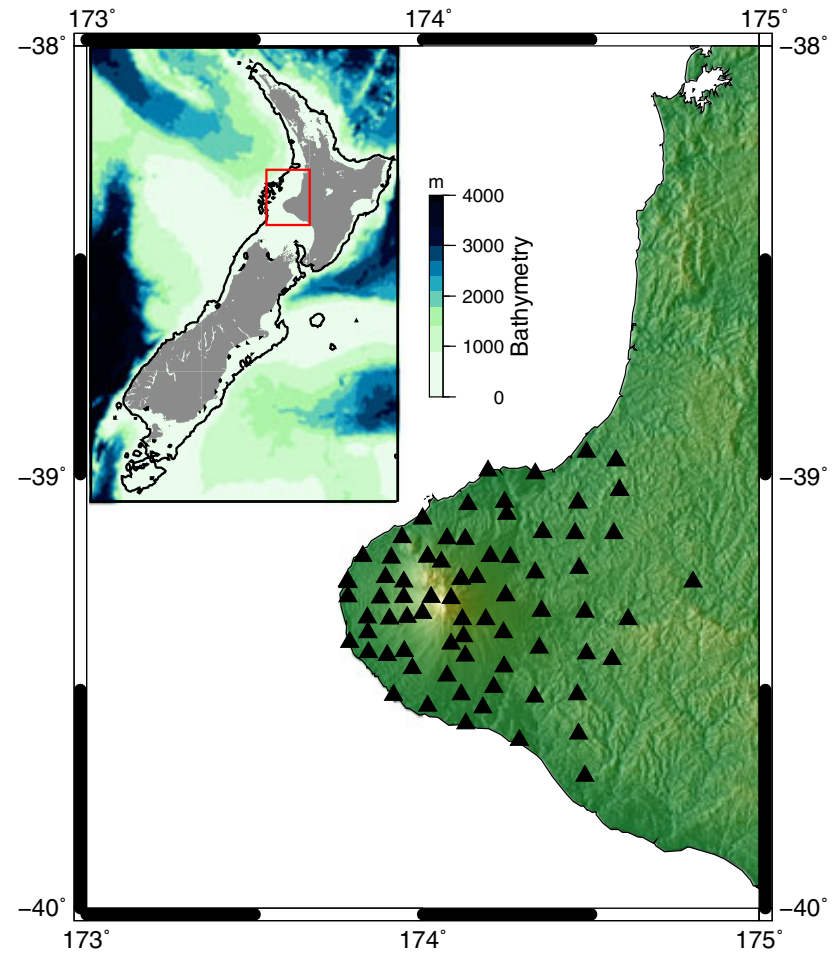

Figure 1. Black triangles mark the locations of the 68 threecomponent broadband stations of the Taranaki deployment operational between March and September 2002. The inset shows the location of the larger map together with the bathymetry around New Zealand taken from the ETOPO2 global relief model (17/9/2012: http://www.ngdc.noaa.gov/mgg/ global/etopo2.html). The black contour marks the shelf area that is shallower than one fourth of the deep-water wave length for waves with periods up to $20 \mathrm{~s}$ period $(140 \mathrm{~m})$.

[9] The cross-covariance matrix $(\mathbf{C})$ is calculated in the frequency domain for each hour-long segment of ambient seismic noise. When processing the horizontal components, the north and east components are rotated into radial and transverse directions corresponding to a presumed wave vector $\vec{k}$ and the cross-covariance matrix is recalculated for every $\vec{k}$ [Poggi and Fäh, 2010]. Radial and transverse components are therefore always relative to the hypothetical source direction.

[10] To mitigate the effects of earthquakes and stationary monochromatic sources, and to balance the spectrum, we apply spectral whitening to the Fourier-transformed traces by setting the spectral amplitudes to unity and only retaining the phase spectrum [Bensen et al., 2007; Stehly et al., 2009]. Because most ambient noise studies using cross-correlations either modify or disregard amplitude information [Shapiro et al., 2005; Stehly et al., 2009; Li et al., 2010], our approach seems reasonable for describing the ambient seismic noise wavefield in this context.

\section{Results}

\subsection{Beamformer Resolution}

[11] Figure 2 shows the array response for monochromatic plane waves arriving from the north, east, south, and west, at 

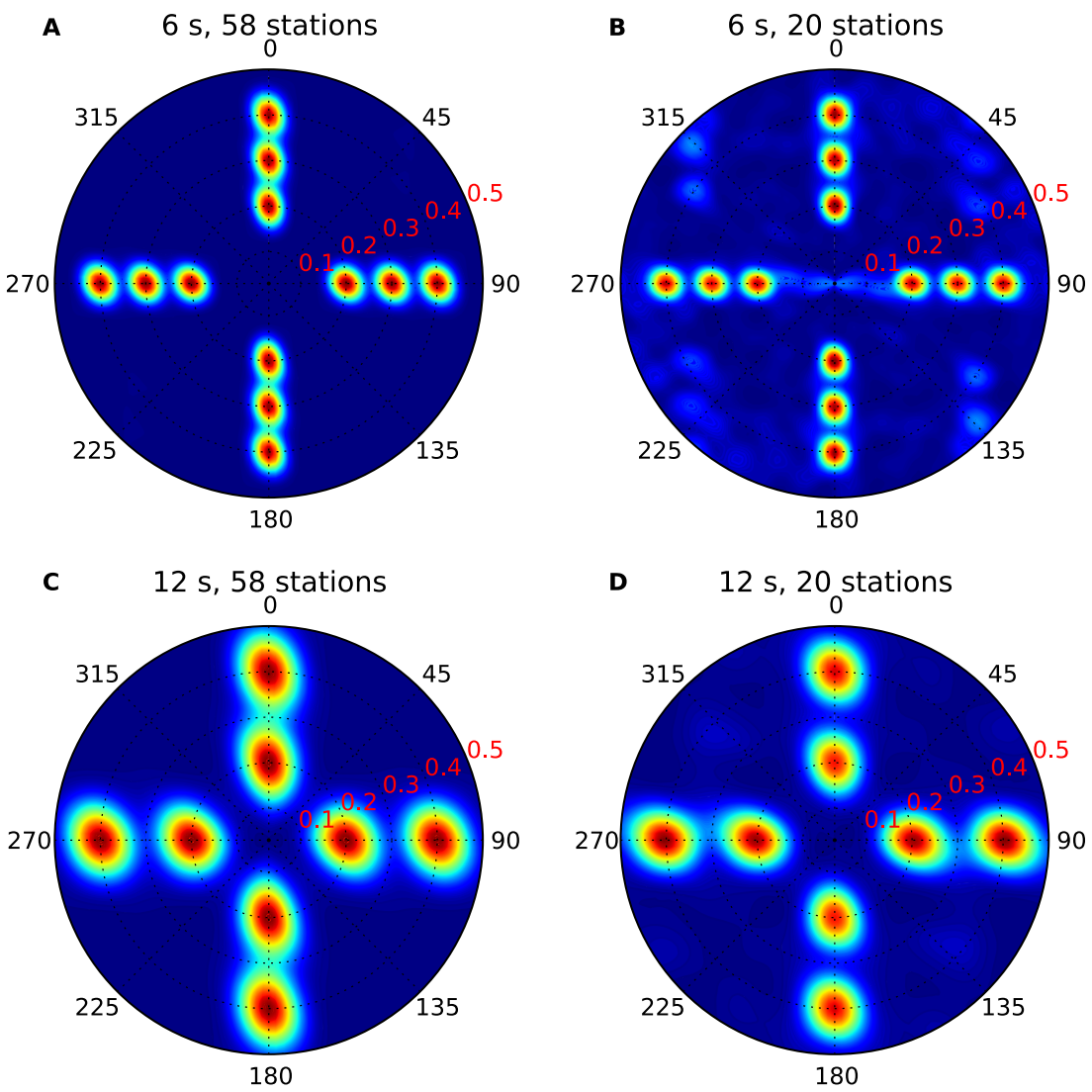

Figure 2. The theoretical array response of the Taranaki deployment for monochromatic plane waves arriving from north, east, south, and west; (A) waves have $6 \mathrm{~s}$ period, slowness values of $0.2,0.3$, and $0.4 \mathrm{~s} / \mathrm{km}$ and 58 stations are operational; (B) the same as Figure 2A but only 20 stations are operational; (C) waves have $12 \mathrm{~s}$ period, slowness values of 0.2 and $0.4 \mathrm{~s} / \mathrm{km}$ and 58 stations are operational; (D) the same as Figure 2c but for only 20 operational stations.

periods of $6 \mathrm{~s}$ (Figures $2 \mathrm{~A}$ and $2 \mathrm{~B}$ ) and $12 \mathrm{~s}$ (Figures $2 \mathrm{C}$ and 2D) and slownesses of $0.2,0.3$, and $0.4 \mathrm{~s} / \mathrm{km}$ for the $6 \mathrm{~s}$ period and 0.2 and $0.4 \mathrm{~s} / \mathrm{km}$ for the $12 \mathrm{~s}$ period. The lefthand panels in Figure 2 show the array response for a day when 58 stations were operational and the right-hand panels for another day when only 20 stations of the Taranaki deployment were operational. In the 20 -station results, which pertain to the minimum number of stations used to produce acceptable beamformer results, side lobes generated by aliasing are noticeable (light blue spots in Figures 2B and 2D) but are considerably lower in amplitude than the main peaks. The requirement of having more than 20 stations operating on any one day was met on more than $85 \%$ of the days analyzed (see Figure S2 in the auxiliary material). The resolution decreases with increasing wave speed (decreasing slowness) and period and also exhibits a slight azimuthal dependence, reflecting the array's geometry. Maxima for 20 stations are better resolved in the north-south direction than for 58 stations, an effect that most likely can also be attributed to differences in the array's geometry. These examples show that the response of an array with irregular station geometry is far from being intuitive (for a detailed discussion on array responses see Wathelet et al. [2008]). Overall, the Taranaki deployment appears suitable for analyzing surface waves within the primary and secondary microseism bands.

\subsection{Beamformer Results}

[12] We compute the beamformer for each of the vertical, radial, and transverse components separately for the whole data set in hourly segments. Because Rayleigh waves are polarized in the vertical-radial plane, the results for the vertical and radial components are largely identical. We therefore restrict the analysis below to the vertical and transverse beamformer results, which correspond to Rayleigh and Love waves respectively. Although some of the Love wave energy is likely to be recorded on the vertical component and some of the Rayleigh wave energy on the transverse component, this approximation seems appropriate within the scope of this study (for a detailed discussion see Roueff et al. [2009]).

[13] Figure 3 shows the beamformer results for the vertical and transverse components at $6 \mathrm{~s}$ (secondary microseism) and $12 \mathrm{~s}$ (primary microseism) periods after taking the logarithm and averaging over the whole data set. As demonstrated by Brooks et al. [2009], higher Rayleigh-wave modes can be detected in the vertical-component Taranaki beamformer results within the period band of the secondary microseism. However, higher Love-wave modes are not apparent in our beamformer results. The decrease in resolution for longer periods shown in Figure 2 can be readily observed. The slowness of Love waves at $6 \mathrm{~s}$ period also appears to be less 

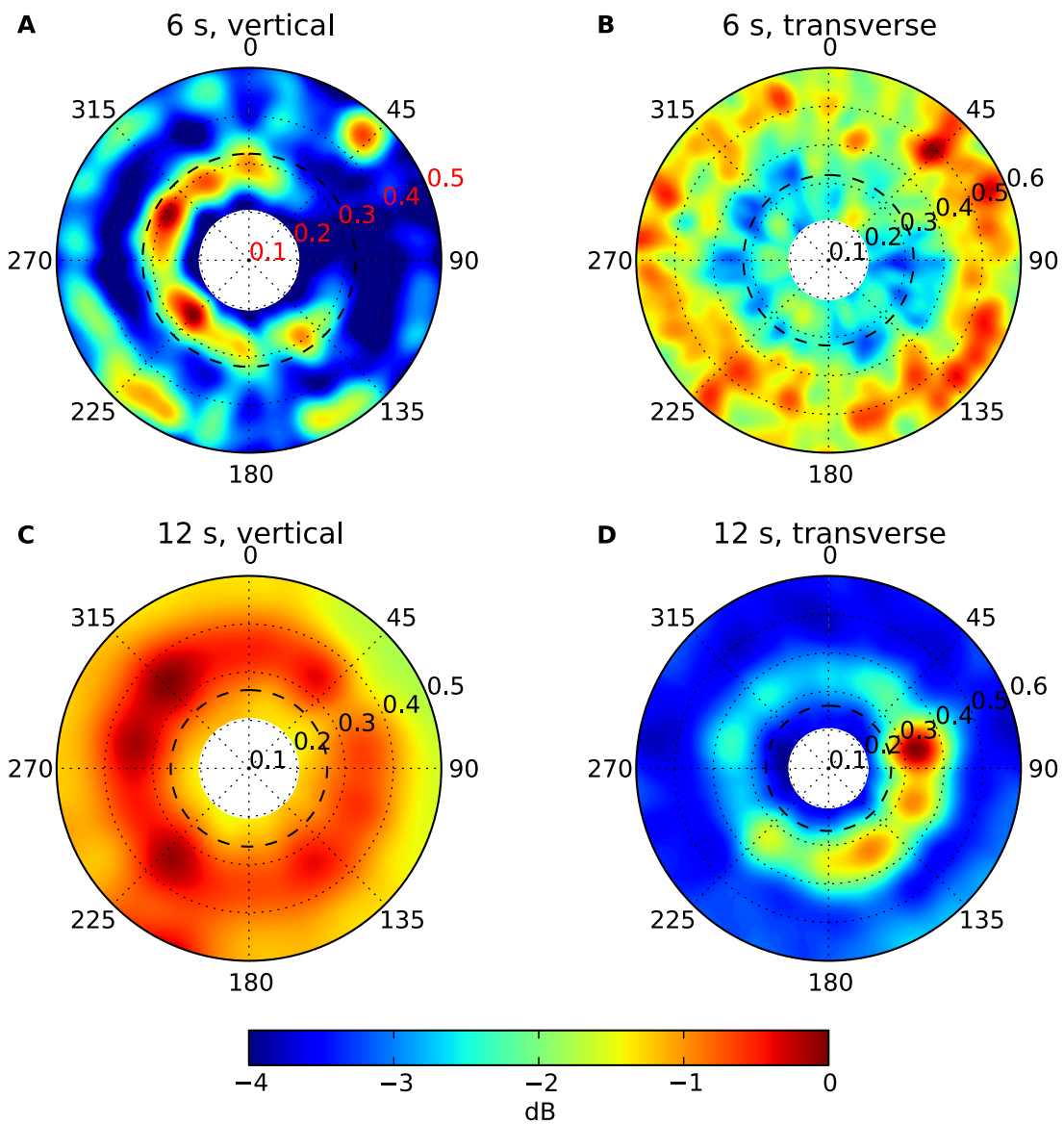

Figure 3. Beamformer results using noise recordings from the Taranaki deployment averaged over days between March and September 2002 when 20 or more stations were operational. (A) The vertical-component and (B) the transverse-component beamformer output at $6 \mathrm{~s}$ period; (C) and (D) The same as Figures $3 \mathrm{~A}$ and $3 \mathrm{~B}$ but for the $12 \mathrm{~s}$ period. The black dashed line marks the minimum of the slowness range over which the results are averaged $(0.32 \mathrm{~s} / \mathrm{km}$ at $6 \mathrm{~s}$ period and $0.26 \mathrm{~s} / \mathrm{km}$ at $12 \mathrm{~s}$ period $)$.

constrained than that of Rayleigh waves of the same period and at $12 \mathrm{~s}$ period the differences between maxima and minima are much smaller for Rayleigh waves than for Love waves.

[14] To better compare the directions from which Rayleigh and Love waves of a certain period arrive at the seismic network, we integrate the beamformer results over the velocity range of the fundamental mode surface wave, normalize the amplitude values to the range $0-1$ and project them in the back-azimuthal direction of the incoming waves (Figure 4). The slowness value in $\mathrm{s} / \mathrm{km}$ that separates the fundamental from higher modes is computed as $6 /(27-50 f)$ where $f$ is the frequency in $\mathrm{Hz}$ of the signal (Brooks et al. [2009], and black dashed line in Figure 3). To facilitate discussion we assign the labels P1-P11 to the dominant source backazimuths.

[15] The dominant source of the vertical-component arrivals within the frequency band of the secondary microseism (Figure 4A) appears to lie to the SW of the array (P8). Another strong source region can be observed NE of the array (P1). Secondary source regions appear to lie SSW (P7), SE (P5), and NNW (P11) of the array. For directions between NE and SE the beamformer results reveal a paucity of strong sources. For directions between NE and east this may be attributed to the Taupo Volcanic Zone (TVZ), a volcanic area in the central North Island, which is known for its strong seismic attenuation [Satake and Hashida, 1989; Behr et al., 2011].

[16] The inferred source directions for waves recorded on the transverse component within the secondary microseism band (Figure 4B) are similar to those on the vertical component. However, the strongest source in this case appears to lie in the NE direction (P1). The inferred source directions are generally more azimuthally restricted than for the vertical component and stronger sources can be discerned between NE and SE azimuths (P1-P5). This may indicate that the TVZ attenuates Love waves less than Rayleigh waves. However, Syuhada [2010] found for the southern TVZ that transverse-component shear waves experience stronger attenuation than radial-component shear waves. Therefore, the absence of sources between P1 and P5 in the vertical-component beamformer may also be attributed to fewer sources of vertical secondary microseisms in these directions.

[17] Within the frequency band of the primary microseism, the vertical-component beamformer (Figure 4C) shows a strong source area in the NW (P10) and WNW (P9) directions, in addition to the strong source region to the SW (P8). Source amplitudes decrease markedly at 

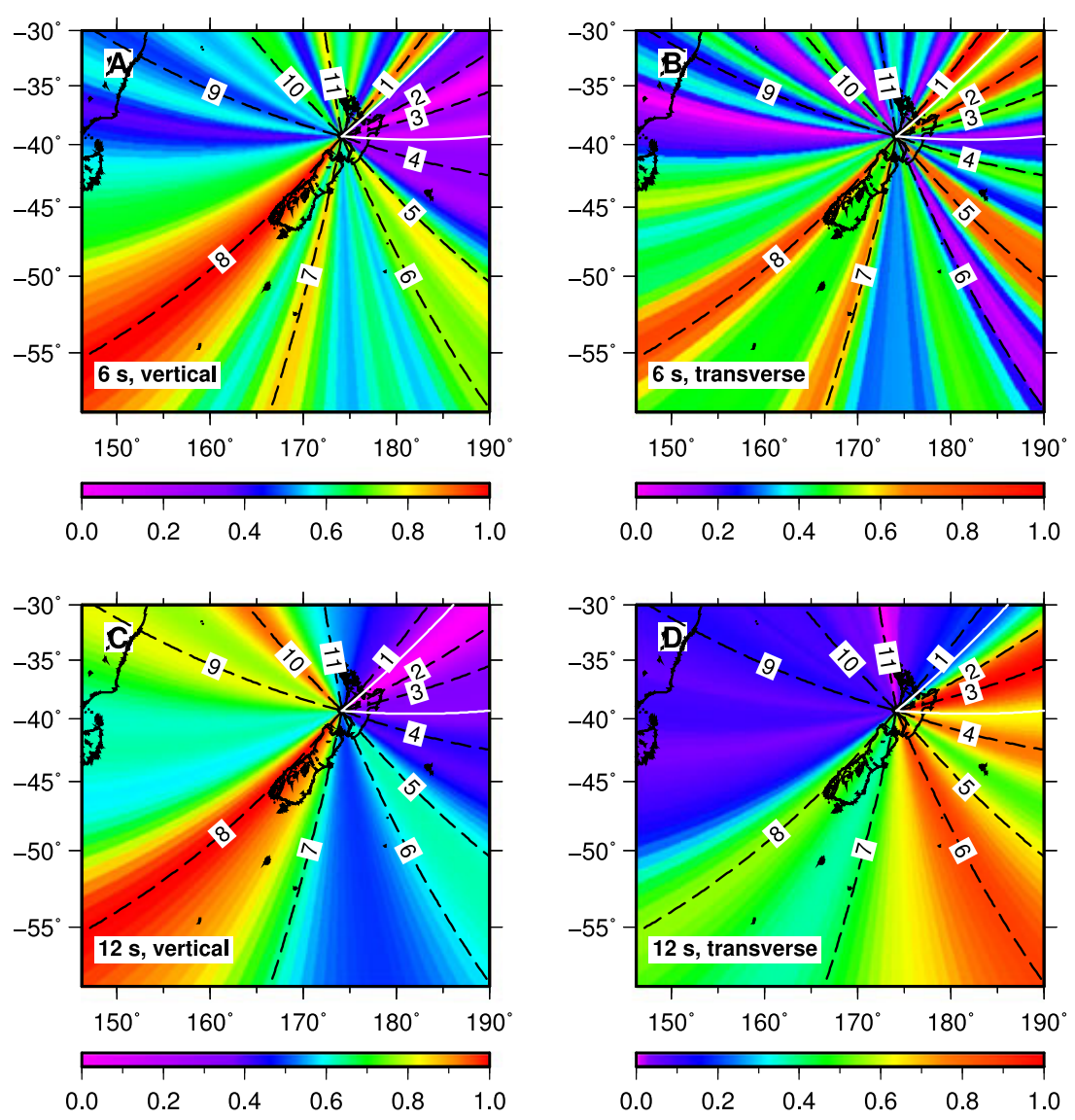

Figure 4. Projection of the beamformer results shown in Figure 3 for (A) the vertical-component and (B) the transverse-component beamformer output at $6 \mathrm{~s}$ period averaged over slownesses corresponding to the fundamental mode. (C) and (D) The same as Figures 4A and 4B but for the $12 \mathrm{~s}$ period. Amplitudes are normalized to range between 0 and 1 and the color palettes are histogram-equalized [Wessel and Smith, 1995]. The black dashed lines mark the dominant source directions discussed in the text and the solid white lines mark the backazimuth range corresponding to the Taupo Volcanic Zone.

NNE-ESE azimuths. The transverse-component beamformer reveals dominant primary microseism source directions to the ENE and SE (P2-P5) and only weak sources between SW and NE directions (Figure 4D). This is in pronounced contrast to the vertical-component beamformer, which yields an almost antithetic source distribution. Secondary source directions on the transverse component can also be observed in the SSW (P7) and SW (P8), the latter being similar to sources seen in the other beamformer results.

[18] Figure 5 shows the beamformer results plotted as a single line for every day of the deployment. At the $6 \mathrm{~s}$ period, dominant source directions show up as discrete bands and the locations of these bands are very similar for Rayleigh and Love waves. This is emphasized by the similarity of the marginal distributions illustrated to the right of each panel. At the $12 \mathrm{~s}$ period, source directions appear to be more azimuthally homogeneous than at the $6 \mathrm{~s}$ period, and differences in the predominant source directions and source strength over time can be seen between the Rayleigh and Love waves. The marginal distributions for Rayleigh and Love waves are almost complementary, with the latter showing high values (e.g., at azimuths of $40-80^{\circ}$ ) where the former shows low values.

\section{Discussion}

\subsection{Secondary Microseism Source Regions}

[19] The results shown in Figures 4A and 4B and Figures 5A and 5B provide strong indications that Rayleigh and Love waves within the secondary microseism band are generated in similar areas. This has also been proposed by Hadziioannou et al. [2012] from colocated observations of horizontal and rotational seismic noise signals in southeastern Germany. The differences in source strengths are possibly caused by local effects in the source region, perhaps related to ocean floor bathymetry [Kedar, 2011]. Because we only have a single array with which to infer source directionality, it is not possible to determine the exact location of the noise-generating regions using triangulation [cf. Rhie and Romanowicz, 2004]. However, using the global model for noise sources in the ocean of Rascle and Ardhuin [2012], which applies the theoretical framework of Longuet-Higgins [1950] to an ocean wave hindcast model [Ardhuin et al., 2010], we can obtain a first-order estimate of possible source regions for the secondary microseism. Longuet-Higgins [1950] showed that the secondary microseism can be attributed to nonlinear interaction between ocean waves of opposing wave vectors. The strength of the resulting pressure fluctuations at the ocean floor 

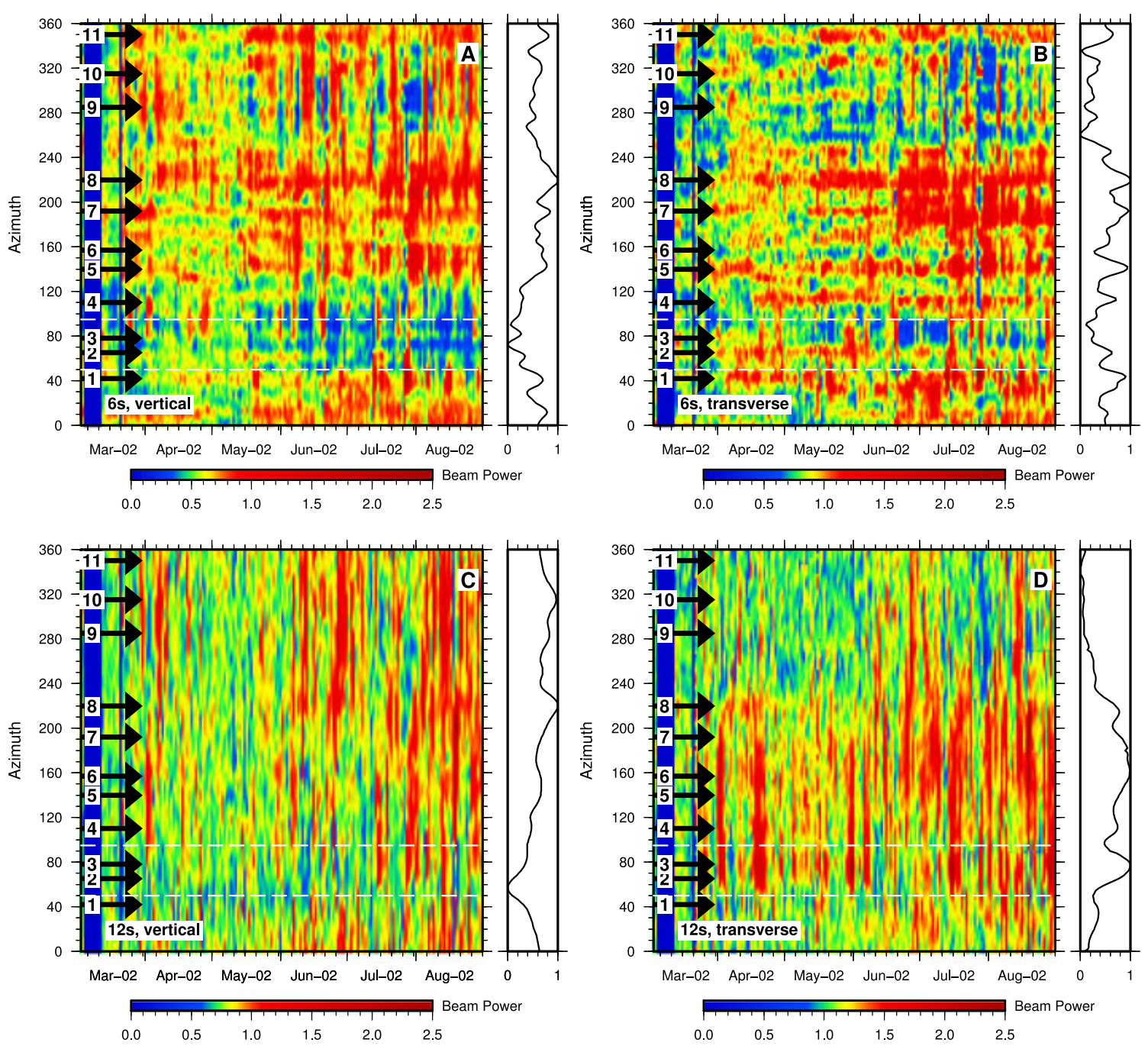

Figure 5. Projection of the beamformer results shown in Figure 4 for every day of the deployment on which 20 or more stations were operational. The small panels display the marginal distribution of the beamformer projections integrated over time and normalized to range between 0 and 1. (A) and (B) The results for the vertical- and transverse-component beamformer at $6 \mathrm{~s}$ period. (C) and (D) The same as Figures $5 \mathrm{~A}$ and $5 \mathrm{~B}$ for $12 \mathrm{~s}$ period. Arrows mark the back-azimuths of the dominant source regions corresponding to the black dashed lines in Figure 4. White dashed lines mark the back-azimuth range of the Taupo Volcanic Zone. The color palettes are histogram-equalized [Wessel and Smith, 1995].

depends not only on the energy of the interfering ocean waves but also on their period and the bathymetry beneath the region of interference.

[20] Figure 6A shows the bathymetric model used (ETOPO01) [Amante and Eakins, 2009] and Figure 6B highlights the potential of the bathymetry to generate seismic noise if it coincided spatially with ocean waves of opposing wave vectors and periods of between 10 and $14 \mathrm{~s}$. Areas of high potential, shown in red, are mostly located along New Zealand's continental margin and along prominent bathymetric features such as Norfolk Ridge and Lord Howe Rise northwest of New Zealand and the Puysegur Margin south of the South Island but also around the coast of Australia and in a wider area in the Southern Ocean south of Australia and New Zealand. Hillers et al. [2012] also identified continental slopes as regions of high excitation potential.
[21] Figures 6C and 6D show theoretical noise sources from the model of Rascle and Ardhuin [2012] averaged for March to August 2002 ignoring and including the effects of interaction between incoming waves and waves reflected from the coastline. It has been proposed by several authors [e.g., Yang and Ritzwoller, 2008; Friedrich et al., 1998; Rhie and Romanowicz, 2004] that much of the secondary microseism energy is generated in coastal areas. Recently, Stutzmann et al. [2012] showed that to model vertical component seismic noise spectra within the frequency band of the secondary microseism both deep-water sources and near-coastal sources are required. The effects of coastal reflections, which correspond to differences between Figures 6C and 6D, are mainly apparent to the SSW in particular in an area close to the coast of the South Island that is crossed by P8, to the NW in an area crossed by P10, and on the south coast of the North Island, which is intersected by P6. 

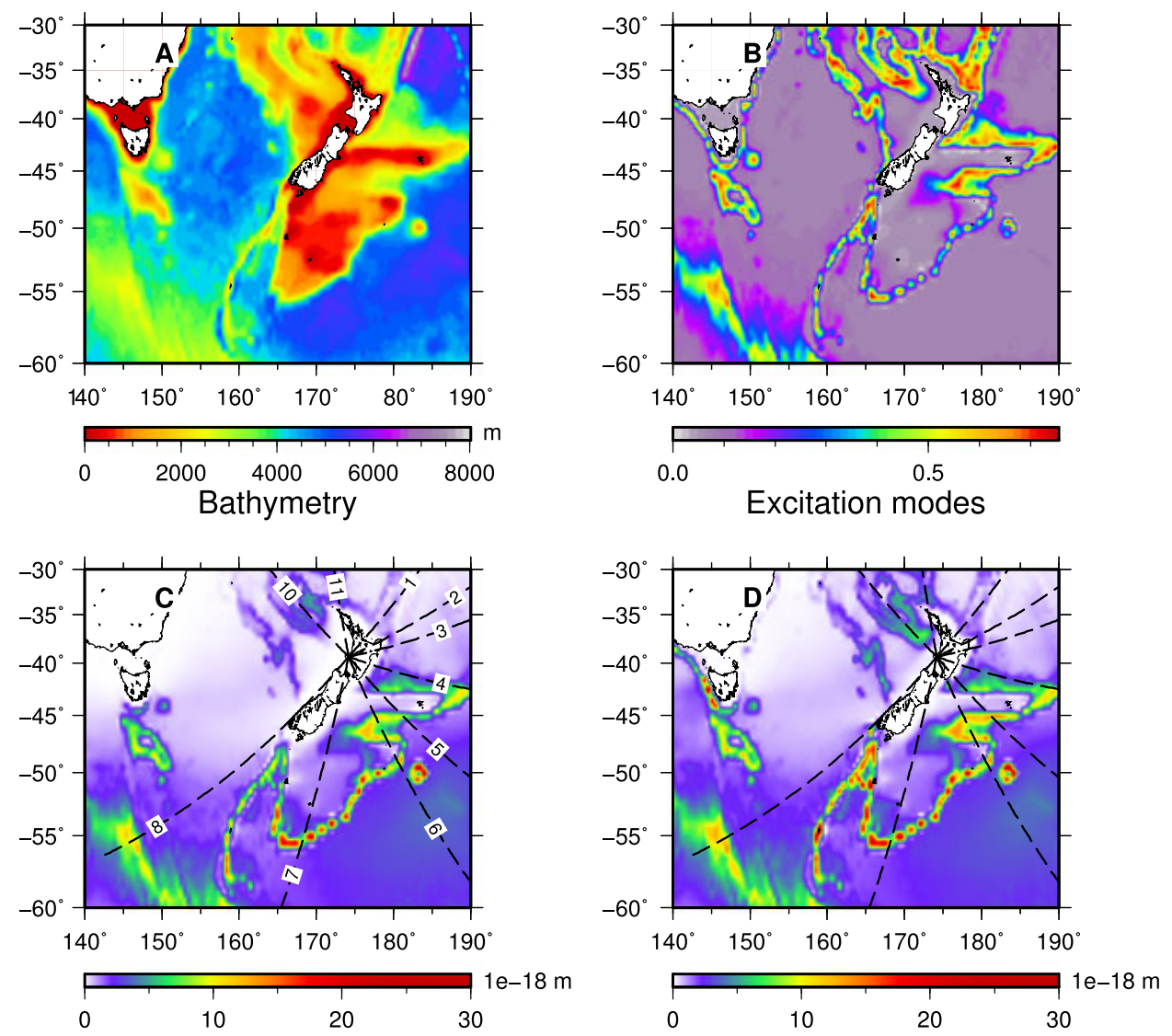

Source regions w/o reflection

Source regions with reflection

Figure 6. (A) Bathymetric model surrounding New Zealand; (B) potential source regions of the secondary microseism based on the elastic excitation modes of Longuet-Higgins [1950] and the bathymetry shown in Figure 6A for periods of 5-7 s. Red areas mark regions with high potential to generate the secondary microseismic signal; (C) theoretical noise source regions from the model of Rascle and Ardhuin [2012] for the secondary microseism for periods of 5-7 s without taking into account coastal reflections of wave energy; the dominant source directions from Figure 4 are also shown; (D) same as Figure 6C including coastal reflections. P9 is not shown because it is only a peak in the primary microseism beamformer result.

[22] The peaks P4-P8 and P10 all point toward strong deepwater sources. P8 and P6 also align with strong near-coastal sources. While the peaks P11-P3 point in the direction of near-coastal and deep-water sources the source strength appears to be less than what is indicated by the beamformer results. An inspection of the wider model area in these directions (not shown here) did not reveal any other obvious potential source areas. However, the coincidence of excitation along the ridge and plateau systems off southern New Zealand raises the possibility of a contribution to seismic noise from fluctuating currents in the deep-reaching Antarctic Circumpolar Current. Many of the beam former peaks coincide with regions of high eddy kinetic energy around the plateau and ridges [Rickard et al., 2005, Figure 2A] suggesting a more careful examination of how these fluctuations in flow may influence seismic noise is warranted. Another possible explanation for the apparent discrepancy is that the source areas generate coherent but not very strong signals. Because we only consider the phase of the noise signal we are unable to distinguish between the two. To more accurately determine the location of a noise source that corresponds to a peak in the beamformer may require different data analysis methods such as spherical beamforming [Zhang et al., 2010] or ray-tracing [Hillers et al., 2012]. This may still, however, lead to ambiguous results when more than one noise source in the same back-azimuthal direction contribute to the recorded noise.

\subsection{Primary Microseism Source Regions}

[23] In contrast to the secondary microseism, the results shown in Figures 4C and 4D and Figures 5C and 5D imply that Rayleigh and Love waves within the primary microseism band are generated in different areas and at different times. Bromirski and Duennebier [2002] suggested that shoaling of deep-water ocean waves on the continental shelf, where it is shallower than one quarter of the deep-water wavelength, makes the biggest contribution to seismic noise energy in the primary microseism band. Wide continental shelves would therefore likely contribute most of the energy within the primary microseism band, since they provide large areas within which deep-water ocean waves can interact with the ocean floor. This appears to be a plausible 
explanation for the energetic waves seen on the vertical component between SW and NE azimuths (P9 and P10) with periods of $\sim 12 \mathrm{~s}$ (Figure $4 \mathrm{C}$ ), since these directions correlate with a wide shelf area around the Taranaki region that is shallower than one fourth of the deep-water wave length for ocean waves with periods up to $20 \mathrm{~s}$ ( $140 \mathrm{~m}$ contour on Figure 1). However, the strong source regions to the SW (P8), NE (P1 and P2), and ESE (P4) coincide with narrow continental shelves. It therefore seems unlikely that shoaling is the only mechanism transferring ocean wave energy into seismic energy in this period range. The source direction to the SW (P8) points toward a coastal area where ocean swells from the SW with high significant wave heights hit a coastline with a very steep continental shelf that drops from sea level to over $4000 \mathrm{~m}$ depth within a horizontal distance of only a few tens of kilometers [Pickrill and Mitchell, 1979]. A narrow and steep shelf area to the east and southeast of the North Island corresponding to peaks P2-P6 also allows moderate- to long-period swells to expend their energy against a narrow $10-20 \mathrm{~km}$ wide continental shelf. This suggests that in addition to shoaling ocean wave energy can also be directly transferred into seismic energy. The differences in source directions for vertical and horizontal noise records further indicate different coupling mechanisms for Rayleigh and Love waves in the primary microseism band.

[24] The difference between the primary and secondary microseism source directions inferred in this study contrasts markedly with the results of Nishida et al. [2008a] who obtained identical source backazimuths for Rayleigh and Love waves from plane-wave beamforming results of horizontal component noise recordings between 10 and $100 \mathrm{~s}$ period in Japan. Further studies employing ambient seismic noise beamforming in different parts of the world may resolve or explain this discrepancy.

[25] Source regions of the primary microseism appear to be distributed more evenly in azimuth than those of the secondary microseism. Friedrich et al. [1998] also observed this phenomenon for noise sources in northern Europe. As indicated by Figure 2, this may be accounted for in our case by the decreased azimuthal resolution of the beamformer results at longer periods. It may also indicate that generation of the secondary microseism requires the coincidence of more specific conditions than required for the primary microseism, or point toward differences in wave propagation between the longer-period primary microseism waves and the shorter-period secondary microseism waves.

\section{Conclusion}

[26] To date, no comprehensive theoretical treatment of the excitation of Love waves for the secondary microseism and no comprehensive theoretical treatment of the excitation of the primary microseism have been derived. We have shown in this study that Rayleigh and Love waves around New Zealand within the secondary microseism period band are mostly generated in the same areas and that these source areas can be attributed to both deep-water and near-coastal source regions. In contrast, there are strong indications that Rayleigh and Love waves within the primary microseism period band have distinctly different source regions. This has important implications for the use of ambient seismic noise for tomographic imaging, especially when inferring
$S_{\mathrm{H}}$ and $S_{\mathrm{V}}$ velocities from Rayleigh and Love wave dispersion curves within the primary microseism band. To identify global patterns of surface wave excitation within the microseism bands, similar studies in other parts of the world will be necessary.

\section{References}

Aki, K., and P. G. Richards (2002), Quantitative Seismology, 2nd ed., 700 pp., University Science Books, Sausalito, Calif.

Amante, C., and B. W. Eakins (2009), ETOPO1 1 Arc-Minute Global Relief Model: Procedures, Data Sources and Analysis, Tech. rep., NOAA Technical Memorandum NESDIS NGDC-24.

Ardhuin, F., et al., (2010), Semi-empirical dissipation source functions for wind-wave models: part I, definition, calibration and validation, J. Phys. Oceanogr., 40(9), 1917-1941.

Behr, Y., J. Townend, S. Bannister, and M. K. Savage (2010), Shear Velocity Structure of the Northland Peninsula, New Zealand, Inferred from Ambient Noise Correlations, J. Geophys. Res., 115(B5), 1-12, doi:10.1029/ 2009JB006737.

Behr, Y., J. Townend, S. Bannister, and M. K. Savage (2011), Crustal shear wave tomography of the Taupo Volcanic Zone, New Zealand, via ambient noise correlation between multiple three-component networks, Geochem., Geophys., Geosyst., 12(3), 1-18, doi:10.1029/2010GC003385.

Bensen, G. D., M. H. Ritzwoller, M. P. Barmin, A. L. Levshin, F.-C. Lin, M. P. Moschetti, N. M. Shapiro, and Y. Yang (2007), Processing seismic ambient noise data to obtain reliable broad-band surface wave dispersion measurements, Geophys. J. Int., 169(3), 1239-1260, doi:10.1111/j.1365-246X.2007.03374.x.

Brenguier, F., M. Campillo, C. Hadziioannou, N. M. Shapiro, R. M. Nadeau, and E. Larose (2008), Postseismic relaxation along the San Andreas fault at Parkfield from continuous seismological observations, Science, 321(5895), 1478-1481, doi:10.1126/science.1160943.

Bromirski, P. D., and F. K. Duennebier (2002), The near-coastal microseism spectrum: Spatial and temporal wave climate relationships, J. Geophys. Res., 107(B8), 1-20, doi:10.1029/2001JB000265.

Brooks, L. A., J. Townend, P. Gerstoft, S. Bannister, and L. Carter (2009), Fundamental and Higher-Mode Rayleigh Wave Characteristics of Ambient Seismic Noise in New Zealand, Geophys. Res. Lett., 36, doi:10.1029/ 2009GL040434.

Curtis, A., Y. Behr, E. Entwistle, E. Galetti, J. Townend, and S. Bannister (2012), The benefit of hindsight in observational science: Retrospective seismological observations, Earth Planet. Sci. Lett., 345-348, 212-220, doi:10.1016/j.eps1.2012.06.008.

Friedrich, A., F. Krüger, and K. Klinge (1998), Ocean-Generated Microseismic Noise Located with the Gräfenberg Array, J. Seismolog., 2, 47-64.

Gorman, R. M., K. R. Bryan, and A. K. Laing (2003), Wave hindcast for the New Zealand region: nearshore validation and coastal wave climate, N.Z. J. Mar. Freshwater Res., 37(3), 567-588.

Hadziioannou, C., P. Gaebler, U. Schreiber, J. Wassermann, and H. Igel (2012), Examining ambient noise using colocated measurements of rotational and translational motion, J. Seismolog., 16(4), 787-796, doi:10.1007/s10950-012-9288-5.

Harmon, N., C. Rychert, and P. Gerstoft (2010), Distribution of noise sources for seismic interferometry, Geophys. J. Int., 183(3), 14701484, doi:10.1111/j.1365-246X.2010.04802.x.

Hillers, G., N. Graham, M. Campillo, S. Kedar, M. Landès, and N. M. Shapiro (2012), Global oceanic microseism sources as seen by seismic arrays and predicted by wave action models, Geochem. Geophys. Geosyst., 13(1), 1-19, doi:10.1029/2011GC003875.

Huang, H., H. Yao, and R. D. van der Hilst (2010), Radial anisotropy in the crust of SE Tibet and SW China from ambient noise interferometry, Geophys. Res. Lett., 37(21), 1-5, doi:10.1029/2010GL044981.

Johnson, D. H., and D. E. Dudgeon (1993), Array Signal Processing: Concepts and Techniques, 132-137 pp., Prentice-Hall, Englewood Cliffs, NJ.

Kedar, S. (2011), Source distribution of ocean microseisms and implications for time-dependent noise tomography, C.R. Geosci., 343(8-9), 548-557, doi:10.1016/j.crte.2011.04.005.

Kedar, S., M. S. Longuet-Higgins, F. Webb, N. Graham, R. Clayton, and C. Jones (2008), The origin of deep ocean microseisms in the North Atlantic Ocean, Proceedings of the Royal Society A: Mathematical, Physical and Engineering Sciences, 464(2091), 777-793, doi:10.1098/rspa.2007.0277.

Kibblewhite, A. C., and K. C. Ewans (1985), Wave-wave interactions, microseisms, and infrasonic ambient noise in the ocean, The Journal of the Acoustical Society of America, 78(3), 981, doi:10.1121/1.392931.

Li, H., F. Bernardi, and A. Michelini (2010), Surface wave dispersion measurements from ambient seismic noise analysis in Italy, Geophys. J. Int., 180(3), 1242-1252, doi:10.1111/j.1365-246X.2009.04476.x. 


\section{BEHR ET AL.: THREE-COMPONENT BEAMFORMING, NEW ZEALAND}

Liang, C., and C. A. Langston (2009), Three-dimensional crustal structure of eastern North America extracted from ambient noise, J. Geophys. Res., 114(B03310), 1-14, doi:10.1029/2008JB005919.

Lin, F.-C., and M. H. Ritzwoller (2010), Empirically determined finite frequency sensitivity kernels for surface waves, Geophys. J. Int., 182(2), 923-932, doi:10.1111/j.1365-246X.2010.04643.x.

Lin, F.-C., M. H. Ritzwoller, J. Townend, S. Bannister, and M. K. Savage (2007), Ambient noise Rayleigh wave tomography of New Zealand, Geophys. J. Int., 170(2), 649-666, doi:10.1111/j.1365-246X.2007.03414.x.

Lin, F.-C., M. P. Moschetti, and M. H. Ritzwoller (2008), Surface wave tomography of the western United States from ambient seismic noise: Rayleigh and Love wave phase velocity maps, Geophys. J. Int., 173, 281-298, doi:10.1111/j.1365-246X.2008.03720.x.

Longuet-Higgins, M. S. (1950), A Theory of the Origin of Microseisms, Philosophical Transactions of the Royal Society A: Mathematical, Physical and Engineering Sciences, 243(857), 1-35, doi:10.1098/ rsta.1950.0012.

Mordret, A., A. D. Jolly, Z. Duputel, and N. Fournier (2010), Monitoring of phreatic eruptions using Interferometry on Retrieved Cross-Correlation Function from Ambient Seismic Noise: Results from Mt. Ruapehu, New Zealand, J. Volcanol. Geotherm. Res., 191, 46-59, doi:10.1016/j. jvolgeores.2010.01.010.

Moschetti, M. P., M. H. Ritzwoller, F.-C. Lin, and Y. Yang (2010), Seismic evidence for widespread western-US deep-crustal deformation caused by extension, Nature, 464(7290), 885-889, doi:10.1038/nature08951.

Nishida, K., H. Kawakatsu, Y. Fukao, and K. Obara (2008a), Background Love and Rayleigh waves simultaneously generated at the Pacific Ocean floors, Geophys. Res. Lett., 35(16), 1-5, doi:10.1029/2008GL034753.

Nishida, K., H. Kawakatsu, and K. Obara (2008b), Three-dimensional crustal S wave velocity structure in Japan using microseismic data recorded by Hi-net tiltmeters, J. Geophys. Res., 113(B10302), 1-22, doi:10.1029/2007JB005395

Petersen, T., K. Gledhill, M. Chadwick, N. H. Gale, and J. Ristau (2011), The New Zealand National Seismograph Network, Seismol. Res. Lett., 82(1), 9-20, doi:10.1785/gssrl.82.1.9.

Pickrill, R. A., and J. S. Mitchell (1979), Ocean wave characteristics around New Zealand, N.Z. J. Mar. Freshwater Res., 13(4), 501-520.

Poggi, V., and D. Fäh (2010), Estimating Rayleigh wave particle motion from three-component array analysis of ambient vibrations, Geophys. J. Int., 180(1), 251-267, doi:10.1111/j.1365-246X.2009.04402.x.

Rascle, N., and F. Ardhuin (2012), A global wave parameter database for geophysical applications. Part 2: model validation with improved source term parameterization, Ocean Modell., doi:10.1016/j.ocemod.2012.12.001.

Rastin, S. J., C. P. Unsworth, K. R. Gledhill, and D. E. McNamara (2012), A Detailed Noise Characterization and Sensor Evaluation of the North Island of New Zealand Using the PQLX Data Quality Control System, Bull. Seismol. Soc. Am., 102(1), 98-113, doi:10.1785/0120110064.

Rhie, J., and B. Romanowicz (2004), Excitation of Earth's continuous free oscillations by atmosphere-ocean-seafloor coupling, Nature, 431(7008), 552-556, doi:10.1038/nature02888.1.

Rickard, G. J., M. G. Hadfield, and M. J. Roberts (2005), Development of a regional ocean model for New Zealand, N.Z. J. Mar. Freshwater Res., 39 (September 2012), 1171-1191.

Roueff, A., P. Roux, and P. Refregier (2009), Wave Separation in Ambient Seismic Noise Using Intrinsic Coherence and Polarization Filtering, Signal Process., 89(4), 410-421, doi:10.1016/j.sigpro.2008.09.008.

Roux, P. (2009), Passive seismic imaging with directive ambient noise: application to surface waves and the San Andreas Fault in Parkfield, CA, Geophys. J. Int., 179(1), 367-373, doi:10.1111/j.1365246X.2009.04282.x.

Roux, P., M. Wathelet, and A. Roueff (2011), The San Andreas Fault revisited through seismic-noise and surface-wave tomography, Geophys. Res. Lett., 38(13), 2009-2012, doi:10.1029/2011GL047811.
Satake, K., and T. Hashida (1989), Three-dimensional attenuation structure beneath North Island, New Zealand, Tectonophysics, 159, 181-194.

Sens-Schönfelder, C., and U. Wegler (2006), Passive image interferometry and seasonal variations of seismic velocities at Merapi Volcano, Indonesia, Geophys. Res. Lett., 33(21), doi:10.1029/2006GL027797.

Shapiro, N. M., and M. Campillo (2004), Emergence of broadband Rayleigh waves from correlations of the ambient seismic noise, Geophys. Res. Lett., 31, 1-4, doi:10.1029/2004GL019491.

Shapiro, N. M., M. Campillo, L. Stehly, and M. H. Ritzwoller (2005), Highresolution surface-wave tomography from ambient seismic noise, Science, 307(5715), 1615-1618, doi:10.1126/science.1108339.

Sherburn, S., and R. S. White (2005), Crustal seismicity in Taranaki, New Zealand using accurate hypocentres from a dense network, Geophys. J. Int., 162(2), 494-506, doi:10.1111/j.1365-246X.2005.02667.x.

Stachnik, J. C., K. Dueker, D. L. Schutt, and H. Yuan (2008), Imaging Yellowstone plume-lithosphere interactions from inversion of ballistic and diffusive Rayleigh wave dispersion and crustal thickness data, Geochem. Geophys. Geosyst., 9(6), 1-21, doi:10.1029/2008GC001992.

Stehly, L., M. Campillo, and N. M. Shapiro (2006), A Study of the Seismic Noise from its Long-range correlation properties, J. Geophys. Res., 111 , doi:10.1029/2005JB004237.

Stehly, L., B. Fry, M. Campillo, N. M. Shapiro, J. Guilbert, L. Boschi, and D. Giardini (2009), Tomography of the Alpine region from observations of seismic ambient noise, Geophys. J. Int., 178(1), 338-350, doi:10.1111/ j.1365-246X.2009.04132.x.

Stutzmann, E., F. Ardhuin, M. Schimmel, A. Mangeney, and G. Patau (2012), Modelling long-term seismic noise in various environments, Geophys. J. Int., no-no, doi:10.1111/j.1365-246X.2012.05638.x.

Syuhada (2010), Seismic Attenuation Anisotropy in the Southernmost Part of the Taupo Volcanic Zone, North Island, New Zealand, Ph.D. thesis, Victoria University of Wellington.

Tindle, C., and M. Murphy (1999), Microseisms and ocean wave measurements, IEEE J. Oceanic Eng., 24(1), 112-115.

Tsai, V. C. (2009), On establishing the accuracy of noise tomography travel-time measurements in a realistic medium, Geophys. J. Int., 178 (3), 1555-1564, doi:10.1111/j.1365-246X.2009.04239.x.

Tsai, V. C. (2010), The relationship between noise correlation and the Green's function in the presence of degeneracy and the absence of equipartition, Geophys. J. Int., 182(3), 1509-1514, doi:10.1111/j.1365246X.2010.04693.X.

Wathelet, M., D. Jongmans, M. Ohrnberger, and S. Bonnefoy-Claudet (2008), Array performances for ambient vibrations on a shallow structure and consequences over Vs inversion, J. Seismolog., 12(1), 1-19.

Wegler, U., H. Nakahara, C. Sens-Schönfelder, M. Korn, and K. Shiomi (2009), Sudden drop of seismic velocity after the $2004 \mathrm{M} \mathrm{w} 6.6$ mid-Niigata earthquake, Japan, observed with Passive Image Interferometry, Journal of Geophysical Research, 114(B6), 1-11, doi:10.1029/2008JB005869.

Wessel, P., and W. H. F. Smith (1995), New version of the Generic Mapping Tools released, Eos Transactions of the American Geophysical Union, 76(329), 329-336.

Yang, Y., and M. H. Ritzwoller (2008), Characteristics of ambient seismic noise as a source for surface wave tomography, Geochem. Geophys. Geosyst., 9(2), doi:10.1029/2007GC001814.

Yang, Y., M. H. Ritzwoller, A. L. Levshin, and N. M. Shapiro (2007), Ambient noise Rayleigh wave tomography across Europe, Geophys. J. Int., 168(1), 259-274, doi:10.1111/j.1365-246X.2006.03203.x.

Yao, H., R. D. Van Der Hilst, and M. V. de Hoop (2006), Surface-Wave Array Tomography in SE Tibet from Ambient Seismic Noise and TwoStation Analysis -I. Phase Velocity Maps, Geophys. J. Int., 166, 732-744, doi:10.1111/j.1365-246X.2006.03028.x.

Zhang, J., P. Gerstoft, and P. D. Bromirski (2010), Pelagic and coastal sources of P -wave microseisms: Generation under tropical cyclones, Geophys. Res. Lett., 37(15), 1-6, doi:10.1029/2010GL044288. 